\title{
Alterations of Blood Brain Barrier Function in Hyperammonemia: An Overview
}

\author{
Marta Skowrońska $\cdot$ Jan Albrecht
}

Received: 11 July 2011/Revised: 12 August 2011/ Accepted: 17 August 2011/Published online: 27 August 2011

(C) The Author(s) 2011. This article is published with open access at Springerlink.com

\begin{abstract}
Ammonia is a neurotoxin involved in the pathogenesis of neurological conditions associated with hyperammonemia, including hepatic encephalopathy, a condition associated with acute-(ALF) or chronic liver failure. This article reviews evidence that apart from directly affecting the metabolism and function of the central nervous system cells, ammonia influences the passage of different molecules across the blood brain barrier (BBB). A brief description is provided of the tight junctions, which couple adjacent cerebral capillary endothelial cells to each other to form the barrier. Ammonia modulates the transcellular passage of low-to medium-size molecules, by affecting their carriers located at the BBB. Ammonia induces interrelated aberrations of the transport of the large neutral amino acids and aromatic amino acids (AAA), whose influx is augmented by exchange with glutamine produced in the course of ammonia detoxification, and maybe also modulated by the extracellularly acting gamma-glutamyl moiety transferring enzyme, gammaglutamyl-transpeptidase. Impaired AAA transport affects neurotransmission by altering intracerebral synthesis of catecholamines (serotonin and dopamine), and producing "false neurotransmitters" (octopamine and phenylethylamine). Ammonia also modulates BBB transport of the cationic amino acids: the nitric oxide precursor, arginine, and ornithine, which is an ammonia trap, and affects the transport of energy metabolites glucose and creatine.
\end{abstract}

M. Skowrońska $\cdot$ J. Albrecht $(\square)$

Departament of Neurotoxicology, Mossakowski Medical

Research Centre, Polish Academy of Sciences, 02-106

Warszawa, Pawińskiego 5, Poland

e-mail: jalb@cmdik.pan.pl
Moreover, ammonia acting either directly or in synergy with liver injury-derived inflammatory cytokines also evokes subtle increases of the transcellular passage of molecules of different size (BBB "leakage"), which appears to be responsible for the vasogenic component of cerebral edema associated with ALF.

Keywords Ammonia neurotoxicity - Hepatic encephalopathy $\cdot$ Blood-brain barrier - Amino acids . Vasogenic brain edema

\section{Introductory Comments}

Homeostasis of the brain is maintained owing to its rigidly controlled communication with the peripheral tissues. Entry of metabolites from the periphery to the brain is controlled by the blood brain barrier (BBB). The major structural constituents of the BBB are the cerebral microvascular endothelial cells, and their barrier function relies on so- called "tight-junctions" (TJs), consisting of transmembrane components: junctional adhesion molecule (JAM)-1, occludin, and the claudins and intracellular proteins: $\mathrm{ZO}-1, \mathrm{ZO}-2$, and $\mathrm{ZO}-3$, which link transmembrane proteins to the actin filaments of cytoskeleton and in this way improve stability and functioning of the TJ. Adherent junctions which are located in the basal region below the TJs, also contribute to the barrier function. Cadherins stabilize adhesion between neighboring endothelial cells, while intracellularly, catenins link cadherins to the cytoskeleton (Fig. 1). The BBB is both physical and metabolic in its nature. Physically, the TJs limit free paracellular diffusion of low molecular weight compounds and make the transcellular transport of larger molecules dependent on specific transport systems, which can be grouped 


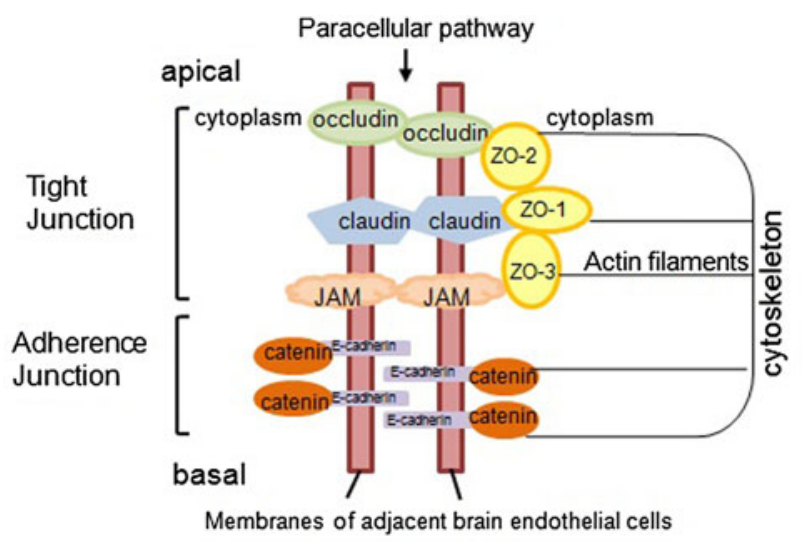

Fig. 1 Composition of the tight junction and adherence junction which collectively restrict the paracellular passage of solutes across the BBB

accordingly to the class of molecules transported (Hawkins and Davis 2005; Carvey et al. 2009). These transport systems are located in endothelial cells, and are modulated both intrinsically and by other cells of the neurovascular unit: astrocytes and pericytes (Simard and Nedergaard 2004). Fine-tuning of the transport involves its polarization by differential location of the transport systems in the luminal versus abluminal membranes, which holds in particular for the different amino acid transport systems (Hawkins et al. 2006). In this way two ultimate and complementary goals are reached: (i) control of the inflow and outflow of metabolic precursors and products, (ii) prevention of entry to the brain of undesired compounds.

The sections below describes the evolution of views on the role of $\mathrm{BBB}$ changes in the pathogenesis of diseases associated with increased exposure of the brain to bloodderived ammonia. "Studies on BBB penetration by different compounds in HE models: a historical account" section gives a historical perspective on the experimental studies on ammonia- and HE-induced changes in BBB penetration of different compounds, without emphasis on the underlying mechanisms. "Transcellular passage of different molecules across the endothelium: roles of active transport" section of the review will elaborate on the relatively well explored subject of modulation of transcellular passage, which represents active transport of medium- to large-molecules, and channel- or transporter-mediated ion fluxes across the capillary endothelial cell membranes. "BBB leakage induced by ammonia and inflammatory molecules: new vistas on the underlying mechanisms" section is devoted to the new findings regarding the mechanisms underlying alterations in the paracellular transport which is defined as BBB leakage, the role of which in ammonia neurotoxicity has so far been underestimated.

\section{Studies on BBB Penetration by Different Compounds in HE Models: A Historical Account}

Pioneering studies pertinent to the effect of ammonia on BBB permeability were performed on animals with portacaval anastomosis (PCA) - a model which mimics the condition of portal-systemic shunting in patients with liver cirrhosis. Laursen et al. (1975) showed that BBB in PCA rats is leaky to horseradish peroxidase (HRP). This observation has been confirmed by Sumner (1982) in a similar experimental setting, and by others using different BBB permeability markers and/or HE models: by Zaki (1983) also in PCA rats who measured amino acid influx using the Oldendorf perfusion technique (Oldendorf 1971), and by Horowitz et al. (1983) in galactosamine-induced animal model of acute liver failure (ALF), where permeability changes to $\alpha$-aminoisobutyric acid were measured. However, other contemporary animal studies often performed in similar HE models and using similar markers, revealed no brain vascular permeability changes. Examples include the absence of changes of sucrose and methylaminoisobutyric acid permeation in galactosamineinduced HE (Lo et al. 1987), and to mannitol or ions in the PCA model (Sarna et al. 1977; Alexander et al. 2000). As will be discussed in "Transcellular passage of different molecules across the endothelium: roles of active transport" and "BBB leakage induced by ammonia and inflammatory molecules: new vistas on the underlying mechanisms" sections, controversies about the BBB status as assessed with different compounds have lasted until the present time, with BBB changes being either confirmed (Wang et al. 2011) or denied (Goldbecker et al. 2010).

Incoherent results were also obtained with regard to the passage of ammonia through the BBB, as monitored with ${ }^{13} \mathrm{~N}$-labeled ammonia (PET technique). Lockwood et al. (1991) showed that ammonia enters the brain more easily in advanced HE patients than in healthy controls. By contrast Goldbecker et al. (2010) did not see any differences in BBB permeability for ammonia between patients with and without liver failure. Sørensen et al. (2007) observed increased ammonia accumulation in cirrhotic patients, but in their hands the increase was solely attributable to increased blood ammonia content.

Understanding of the effects of hyperammonemia on ammonia passage will require separate analysis of the two different forms of ammonia. At physiological $\mathrm{pH}$ overwhelming proportion of ammonia occurs as a cation (Warren 1962), so it enters the brain mainly by a transcellular route, using an array of potassium channels and transporters or by substituting other cations with similar hydrated radius (Ott and Larsen 2004). One article indicated the presence of a specific $\mathrm{NH}_{4}{ }^{+}$carrier the Rhesus associated glycoprotein RhCG in the brain capillaries 
(Huang and Liu 2001) but its location (luminal vs. abluminal side) and functionality remains to be confirmed. However, recently the pericellular penetration by gaseous ammonia is being taken under consideration as a significant alternative (Ott and Larsen 2004). It is not known which of the two routes would be affected under excessive ammonia load.

On the top of these controversies, increased vesicular transport across endothelial cells and swelling of astrocytic end-feet has been observed in different HE models (Pilbeam et al. 1983), with TJs remaining intact (Kato et al. 1992). It would thus appear that altered transcellular passage maybe a frequent phenomenon, albeit BBB changes in $\mathrm{HE}$ are often too subtle to be detected with markers of gross BBB leakage.

\section{Transcellular Passage of Different Molecules Across the Endothelium: Roles of Active Transport}

\section{Amino Acids}

PCA in rats is associated with amino acid imbalance in CSF and brain due to enhanced blood to brain transport of tryptophan and other members of large neutral amino acid group (LNAA) (James et al. 1978). In addition, increased concentration of aromatic amino acids (AAA) was found in brains of rats with PCA, while the level of branched-chain amino acids was decreased (Smith et al. 1978). The above observations prompted a hypothesis that these alterations may contribute to impaired neurotransmission in $\mathrm{HE}$ by producing (i) excessive amounts of neurotransmitters from which they derive, and/or (ii) "false" instead of "authentic" neurotransmitters, which are similar in structure but are either not active at the postsynaptic membrane, or their activity differs from their "true" counterparts (Curzon et al. 1975). The "false neurotransmitter" hypothesis appears attractive, because AAA are also precursors of these "false" modulators: tyrosine for octopamine; phenylalanine for phenylethanolamine. Indeed, James et al. (1976) and Cangiano et al. (1982) showed elevated brain octopamine and phenylethanolamine levels in the brains of PCA rats, and Hilgier et al. (1985) in the brains of rats with thioacetamide-induced liver failure. However, the contribution of these false neurotransmitters to the neurotransmission imbalance associated with $\mathrm{HE}$ has insofar not been examined in more detail.

A plausible explanation for the ammonia-induced increase of blood-brain AAA transport activity was proposed by James and colleagues (1979) who hypothesized that during hyperammonemia, increased brain glutamine (Gln) production is followed by increased Gln efflux from the brain, resulting in increased inward transport of these amino acids. This inference has been proven directly in studies in which increased tryptophan (Try) uptake in exchange with Gln via the L-transport system was recorded in cerebral capillary microvessels isolated from PCA rats (Cangiano et al. 1983). Vice versa, release of newly loaded Gln from the capillaries was promoted by the Try and leucine (Leu), and the effect was more pronounced when the capillaries were isolated from TAA rats or following their incubation with ammonia than in control preparations (Hilgier et al. 1992). In the in situ setting, Rigotti et al. (1985) showed that treatment of PCA rats with an inhibitor of Gln synthesis, methionine sulfoximine (MSO), reduced the increased accumulation of the AAA in the brain in a manner correlated with increased ammonia accumulation. Furthermore, Hawkins et al. (1993) showed that administration of MSO to PCA rats normalized amino acid imbalance ascribed to excessive Gln production.

Hyperammonemia was shown to be directly responsible for PCA-induced alterations in the metabolism and transport of amino acids (Jessy et al. 1990), including elevated brain Try content and rise in the brain level of a serotonin metabolite, 5-hydroxyindoleacetic acid. These effects appeared to be due to ammonia-induced functional impairment of LNAA transport at the BBB. In rats in which HA was executed by urease administration, the impairment was found closely correlated with the rise in brain Gln content (Bachmann and Colombo 1983), while in the cortical capillaries the increased Try-Gln exchange could be related to the raised $\gamma$-glutamyl-transpeptidase (GGT) activity (Stastný et al. 1988). Because GGT participates in LNAA transport and its activity was found to be increased in brain capillaries from hyperammonemic rats, a hypothesis has been put forward that GGT is involved in triggering the outward transport of the excess of Gln from brain (Gorgievski-Hrisoho et al. 1986). In this way, enhanced activation of GGT could contribute to raised Try and other LNAA levels as observed in rats with TAAinduced ALF (Hilgier et al. 1990). The above speculations were confirmed in a follow up study from the author's laboratory showing that GGT affects the L system-mediated amino acid exchange (Hilgier et al. 1992).

The BBB transport of the cationic amino acids arginine (Arg) and ornithine (Orn) was investigated in different HE models, and contradictory results have been obtained. Zaki et al. (1984) showed a 30\% increase in the brain uptake of Arg in the galactosamine model of hepatic failure; however, the effect was not specific to this amino acid and possibly secondary to BBB leakage also revealed by high molecular weight markers. By contrast, Arg uptake from blood to brain was found decreased in chronic HE (PCA) rats (Zanchin et al. 1979) and in rats with thioacetamide (TAA)-induced HE (Albrecht et al. 1996). With regard to Orn, increased brain uptake index of this amino acid 
coincident with its increased content in the blood was found in the TAA model of HE (Albrecht and Hilgier 1986; Albrecht et al. 1994 1996; Albrecht et al. 1996). Increased BBB transport of Orn in the TAA model has been considered as auto-protective response and in the same line has been speculated to facilitate intracerebral therapeutic action of the ammonia-trapping drug, L-ornithine-L-aspartate (LOLA) (Albrecht et al. 1994; Albrecht et al. 1996). However, the benefits of Orn may not apply to $\mathrm{HE}$ in a chronic setting, where blood to brain transport of Orn appears to remain unchanged (Zanchin et al. 1979).

The mechanism underlying alterations of BBB transport of Arg and Orn has been hypothesized to involve changes in the basic amino acid transporter $\mathrm{y}^{+}$activity and competition between these two amino acids for the transport site (Albrecht et al. 1996), but experimental evidence in support of this hypothesis has not been provided as yet. The effects of HE on Arg transport are also likely to be mediated by Gln, which accumulates intracerebrally in consequence of increased ammonia influx (Cooper and Plum 1987), overloading different cellular and subcellular compartments of the CNS (Albrecht 2010). It has been shown that Gln added exogenously reduces NO generation in the brain by inhibiting Arg transport via the Arg/Gln exchanger, $\mathrm{y}^{+}$LAT2, and that this effect is potentiated when ammonia is infused directly to the brain (Hilgier et al. 2009), or accumulates in there during HE (Zielińska et al. 2011). If the above mechanism operates not only in the CNS cells but also in the cerebral capillary endothelial cells forming the BBB, enhanced Gln accumulation would modulate Arg transport in these cells. The final outcome of this interaction would depend on whether Gln accumulates intra- or extra-cellularly. A hypothesis that such an interaction may occur is supported by the observation that, Gln infusion in the absence of hyperammonemia impairs cerebrovascular $\mathrm{CO}_{2}$ reactivity, most likely by reducing Arg availability and NO synthesis, because co-infusion of Arg counteracts the effect caused by glutamine (Okada et al. 2000). Consistent with the role of Arg/Gln exchange at the $\mathrm{BBB}$, our preliminary data indicate that ammonia increases the expression of the $\mathrm{y}^{+}$LAT2 transporter in a cerebral capillary endothelial cell line (manuscript in preparation), as it does in the brain in the course of HA in situ (Zielińska et al. 2011).

Further studies on the mechanisms and pathophysiological implications of the changes in Arg or Orn influx to the brain are warranted in view of the proven or suspected contributions of the amino acids to the pathogenesis of HE. Arg is a precursor of NO, a compound whose increased accumulation is engaged in the inflammatory response of the brain to ammonia (Jalan et al. 2011), and in ammoniainduced brain swelling (Häussinger and Görg 2010), while decreased NO synthesis has been implicated in impairment of cognition associated with prolonged hyperammonemia (Felipo 2006). Moreover, HA increases Arg uptake to the different cell types within the CNS (Rao et al. 1997; Hazell et al. 1998), and HE in the TAA model stimulates Arg conversion to the neurotransmitter amino acids Glu and GABA as measured in the whole brain (Albrecht and Hilgier 1986) and in synaptosomes derived from these rats, which is likely to alter the balance between the inhibitory and excitatory neurotransmission (Albrecht et al. 1990). Evaluation of the contribution of changes in Arg transport across the BBB to the availability of this amino acid in the brain cannot be accomplished without accounting for the variability in blood Arg content in the different hyperammonemic models. The plasma Arg level was shown to be decreased in PCA rats (Zanchin et al. 1979), but was elevated in rats subjected to prolonged hyperammonemia (Ishihara et al. 1998), and fluctuated from increase to decrease during the development of TAA-induced HE (Albrecht and Hilgier 1986).

Orn plays a role in ammonia detoxification and gives rise to polyamines which exert hepato- and neuroprotection (Sikorska et al. 2010; Seiler 2000). Treatment with LOLA, where Orn contributes to urea formation, reduces blood ammonia level and in consequence improves the general condition of HE patients (Kircheis et al. 2002; Toris et al. 2011). In this light, increased brain uptake of Orn as found in the TAA model of HE would further promote protection (Albrecht et al. 1994).

Orn also contributes in some degree to the biosynthesis of the neurotransmitter amino acids Glu and GABA (Shank and Campbell 1983). Similar to Arg, conversion of its product Orn to Glu/GABA is stimulated during $\mathrm{HE}$ (Albrecht and Hilgier 1986; Albrecht et al. 1990). However, implications for this increased conversion for neurotransmission imbalance associated with $\mathrm{HE}$ are not known.

Taurine (Tau) is a sulfur amino acid largely implicated in osmoregulatory and neuroprotective responses of the brain in various diseases, including hyperammonemia and HE (Bosman et al. 1992; Butterworth 1996; Faff et al. 1997; Zielinska et al. 2003). Volume regulatory properties of Tau are thought to be of particular importance in the case of brain edema, a major consequence of hyperammonemia, which results from impaired water homeostasis followed by swelling of astrocytes (Blei 2005). HE but not HA was associated with elevated blood content and increased brain uptake from blood to brain of Tau, which collectively contributed to the increase of Tau level in cerebral cortex (Hilgier et al. 1996). Similar observation that liver failure induces elevation of Tau in the blood were also made by other authors (Hamberger and Nyström 1984; Zimmermann et al. 1989). Because increased passage of Tau was not due to massive breakdown of BBB 
(as manifested by the absence of penetration of L-aspartate, which is not transported by intact capillary endothelial cells), it was believed to reflect activation of a Tau transport system (Hilgier et al. 1996). Of note in this context, treatment of an endothelial cell line with ammonia led to up-regulation and increased function of Tau transporter (Bélanger et al. 2007).

\section{Energy Substrates}

Hyperammonemia by affecting BBB transport of different substances and molecules can also lead to disturbances in cerebral energy homeostasis. Hepatic encephalopathy evoked by PCA was demonstrated to be associated with decreased brain glucose use and energy metabolism (DeJoseph and Hawkins 1991), and a similar effect was noted in rats with TAA-induced HE (Hilgier et al. 1991). Brain uptake index of glucose was reduced after PCA in rats (Sarna et al. 1979; Crinquette et al. 1982) and this decrease was almost entirely due to the decrease in plasma glucose concentrations (Mans et al. 1986). GLUT-1, the principal glucose transporter at the BBB responsible for supplying CNS cells with blood-borne glucose was demonstrated to be induced by ALF (Bélanger et al. 2006). Since inhibition of glucose oxidative metabolism and subsequent activation of cerebral glycolysis are a hallmark of brain energy metabolism in HE animals (Zwingmann et al. 2003; Rao and Norenberg 2001), increased expression of GLUT-1 maybe considered as a compensatory response aimed at supporting higher glycolysis and maintaining brain ATP levels.

Creatine $(\mathrm{Cr})$ a key substrate of the creatine/phosphocreatine/creatine kinase pathway is involved in regeneration of ATP and in this way it also contributes to brain energy metabolism. Moreover, $\mathrm{Cr}$ was shown to affect GABA-ergic neurotransmission by acting as partial agonist on post-synaptic GABA(A) receptors (Cupello et al. 2008) and to be crucial in dendritic and axonal elongation (Braissant et al. 2002). Exposure to ammonia was shown to generate a deficiency in $\mathrm{Cr}$ in CNS cells and to lead to neuronal cell loss, while co-treatment with $\mathrm{Cr}$ was neuroprotective under ammonia exposure, but only in the presence of astrocytes (Braissant 2002). Ammonia treatment was demonstrated to increase $\mathrm{Cr}$ uptake in cultured microcapillary brain endothelial cells (Bélanger et al. 2007), which probably reflects a neuroprotective response.

\section{BBB Leakage Induced by Ammonia and Inflammatory Molecules: New Vistas on the Underlying Mechanisms}

Recent studies confirmed the view that hyperammonemia produces subtle changes in BBB integrity and partly unraveled the underlying mechanism. Brain extravasation and edema in azoxymethane-induced ALF were found to be secondary to tight junction (TJ) protein degradation mediated by activation of matrix metalloproteinase- 9 (MMP-9) (Nguyen et al. 2006). Specifically, it has been shown that TJ proteins occludin and claudin-5 are significantly degraded in the brains of mice with galactosamineinduced ALF, and this effect was reversed by treatment with inhibitor of MMP-9, GM6001 (Chen et al. 2009). A recent study delineated the most likely sequence of events linking activation of MMP-9 to occludin degradation in ALF mice; the intermediate steps include transactivation of epidermal growth factor receptor (EGFR) and p38 MAPK/ $\mathrm{NF} \kappa \mathrm{B}$ (mitogen-activated protein kinase/nuclear factorkappa B) (Chen et al. 2011). Cauli et al. (2011) observed that progression of intracranial pressure in the course of ALF is strictly correlated with the increase in BBB permeability and MMP-9 content. Basing on this study the authors proposed a sequence of events of ALF-induced brain damage, in which increase in $\mathrm{BBB}$ permeability is an initial step leading to vasogenic edema followed by ammonia excitotoxicity and cytotoxic edema.

Inflammatory molecules, including cytokines (IL-1 and/ or IL-6) and tumor necrosis factor-alpha (TNF- $\alpha$ ) are increased in plasma during acute and chronic liver failure in patients (Tilg et al. 1992; Wright et al. 2007), and in animals with experimentally-induced HE (Jiang et al. 2009). Circulating levels of TNF- $\alpha$ correlate positively with the severity of HE (Odeh et al. 2005), moreover, its involvement in the development of intracranial pressure in patients with ALF was demonstrated (Jalan et al. 2004). Plasma IL-6 level was also found well correlated with the severity of $\mathrm{HE}$ and morbidity of the patients (Sheron et al. 1991). Because massive breakdown of $\mathrm{BBB}$ is not observed during $\mathrm{HE}$, it is believed that the effects of inflammatory cytokines are transduced to the CNS by vasoactive agents such as nitric oxide or prostanoids, which are synthesized by BBB-forming endothelium (Licinio and Wong 1997). However, TNF- $\alpha$ was recently shown to directly affect the blood-brain barrier permeability in ALF animals in the galactosamine (Lv 2010) and APAP model (Wang et al. 2011) and in human ALF patients (Lv 2010), by disrupting TJs and inducing loss of the TJ-associated protein occludin (Lv 2010).

\section{Conclusions and Perspectives}

Data presented in this review provide considerable evidence that ammonia alters the passage of different molecules across the $\mathrm{BBB}$, both by the transcellular route representing active or facilitated transport, and paracellularly, which occurs due to changes in the integrity of $\mathrm{BBB}$ constituents and thus reflects BBB leakage. As discussed above, increased BBB permeability adds a vasogenic 
component to the cytotoxic brain edema associated with HE (Cauli et al. 2011).

The effects of ammonia on the carrier-mediated transport of different molecules by the cerebral endothelial cells have been studied in considerable detail and the outlines of the changes in amino acid or energy metabolite transport are relatively well described. By contrast, the transcellular transport has long been given little consideration, mainly because in most HE models, the ammonia-or HE-induced changes have been too subtle and spatially restricted to be visualized by standard light- and electron microscopic techniques. The advent of more sensitive techniques has made it possible to identify the changes in TJ proteins and their environment in a microscale, and provided tools to bridge the observations to the molecular mechanisms underlying the BBB leakage. Further studies in this direction should allow to distinguish between the BBB changes in HE which are induced directly by ammonia and those related to inflammatory toxins, mostly cytokines. One aspect deserving consideration in the future studies is the potential role of free radicals of oxygen and nitrogen, which have been found to be generated in excess by ammonia in different models and cell types of the CNS and are responsible for the oxidative/nitrosative stress (ONS) (Bemeur et al. 2010; Häussinger 2010; Skowrońska et al. 2010). Preliminary results from our laboratory disclosed that ONS markers accumulate in an ammonia-treated brain microvascular endothelial cell line and increase permeability of these cells to a high molecular weight marker (Skowrońska et al., manuscript in preparation). This line of investigation appears attractive in view of the fact that ONS causes BBB dysfunction in brain pathologies of varying etiology and severity (Lehner et al. 2011). Many of the intracellular derangements known to be induced by ammonia in the cells within the CNS or in peripheral tissues are likely to hold for the BBB-forming cerebral vascular endothelial cells, and may converge with events triggered in the different cells by ONS. Of note activation of the p38 MAPK/NF $\kappa$ B pathway which underlies MMP-9induced TJ protein damage (Chen et al. 2011), is also involved in ammonia-induced oxidative damage of astrocytes (Jayakumar et al. 2006; Sinke et al. 2008). Other targets may include, for instance, altered Nrf2-mediated synthesis of heme oxygenase I, an effect common to the response to various blood brain barrier damaging conditions (Lehner et al. 2011) and to the ammonia-induced ONS in astrocytes (Warskulat et al. 2002). Clearly, the above described mechanisms do not exhaust the list of possibilities that are worth further investigation.

Acknowledgments Supported by Ministry of Science and Education (National Research Centre) grant no N N401 130839.
Open Access This article is distributed under the terms of the Creative Commons Attribution Noncommercial License which permits any noncommercial use, distribution, and reproduction in any medium, provided the original author(s) and source are credited.

\section{References}

Albrecht J (2010) Hepatic encephalopathy in our genes? Ann Intern Med 153:335-336

Albrecht J, Hilgier W (1986) Arginine in thioacetamide-induced hepatogenic encephalopathy in rats: activation of enzymes of arginine metabolism to glutamate. Acta Neurol Scand 73:498501

Albrecht J, Hilgier W, Rafałowska U (1990) Activation of arginine metabolism to glutamate in rat brain synaptosomes in thioacetamide-induced hepatic encephalopathy: an adaptative response? J Neurosci Res 25:125-130

Albrecht J, Hilgier W, Januszewski S, Kapuściński A, Quack G (1994) Increase of the brain uptake index for L-ornithine in rats with hepatic encephalopathy. Neuroreport 5:671-673

Albrecht J, Hilgier W, Januszewski S, Quack G (1996) Contrasting effects of thioacetamide-induced liver damage on the brain uptake indices of ornithine, arginine and lysine: modulation by treatment with ornithine aspartate. Metab Brain Dis 11:229-237

Alexander B, Li X, Benjamin IS, Segal MB, Sherwood R, Preston JE (2000) A quantitative evaluation of the permeability of the blood brain barrier of portacaval shunted rats. Metab Brain Dis 15:93-103

Bachmann C, Colombo JP (1983) Increased tryptophan uptake into the brain in hyperammonemia. Life Sci 33:2417-2424

Bélanger M, Desjardins P, Chatauret N, Butterworth RF (2006) Selectively increased expression of the astrocytic/endothelial glucose transporter protein GLUT1 in acute liver failure. Glia 53:557-562

Bélanger M, Asashima T, Ohtsuki S, Yamaguchi H, Ito S, Terasaki T (2007) Hyperammonemia induces transport of taurine and creatine and suppresses claudin-12 gene expression in brain capillary endothelial cells in vitro. Neurochem Int 50:95-101

Bemeur C, Desjardins P, Butterworth RF (2010) Evidence for oxidative/nitrosative stress in the pathogenesis of hepatic encephalopathy. Metab Brain Dis 25:3-9

Blei AT (2005) The pathophysiology of brain edema in acute liver failure. Neurochem Int 47:71-77

Bosman DK, Deutz NEP, Maas MAW, Van Eijk HMW, Smit JJH, De Haan JG, Chamuleau RAFM (1992) Amino acid release from cerebral cortex in experimental acute liver failure, studied by in vivo cerebral cortex microdialysis. J Neurochem 59:591-599

Braissant O, Henry H, Villard AM, Zurich MG, Loup M, Eilers B, Parlascino G, Matter E, Boulat O, Honegger P, Bachmann C (2002) Ammonium induced impairment of axonal growth is prevented through glial creatine. J Neurosci 22:9810-9820

Butterworth RF (1996) Taurine in hepatic encephalopathy. Adv Exp Med Biol 403:601-606

Cangiano C, Farber MO, Cardelli-Cangiano P, Rossi-Fanelli F, Cascino A, Capocaccia L, Cockerill EM, Manfredi F (1982) Plasma levels of false neurotransmitters across the brain in portal-systemic encephalopathy. Eur J Clin Invest 12:15-21

Cangiano C, Cardelli-Cangiano P, James JH, Rossi-Fanelli F, Patrizi MA, Brackett KA, Strom R, Fischer JE (1983) Brain microvessels take up large neutral amino acids in exchange for glutamine. Cooperative role of $\mathrm{Na}^{+}$-dependent and $\mathrm{Na}^{+}$-independent systems. J Biol Chem 258:8949-8954 
Carvey PM, Hendey B, Monahan AJ (2009) The blood-brain barrier in neurodegenerative disease: a rhetorical perspective. J Neurochem 111:291-314

Cauli O, López-Larrubia P, Rodrigo R, Agusti A, Boix J, NietoCharques L, Cerdán S, Felipo V (2011) Brain region-selective mechanisms contribute to the progression of cerebral alterations in acute liver failure in rats. Gastroenterology 140:638-645

Chen F, Ohashi N, Li W, Eckman C, Nguyen JH (2009) Disruptions of occludin and claudin-5 in brain endothelial cells in vitro and in brains of mice with acute liver failure. Hepatology 50:1914-1923

Chen F, Hori T, Ohashi N, Baine AM, Eckman CB, Nguyen JH (2011) Occludin is regulated by epidermal growth factor receptor activation in brain endothelial cells and brains of mice with acute liver failure. Hepatology 53:1294-1305

Cooper AJ, Plum F (1987) Biochemistry and physiology of brain ammonia. Physiol Rev 67:440-519

Crinquette JF, Boschat M, Rapin JR, Delorme ML, Opolon P (1982) Early changes in blood-brain barrier permeability after portocaval shunt and liver ischaemia. Clin Physiol 2:241-250

Cupello A, Balestrino M, Gatta E, Pellistri F, Siano S, Robello M (2008) Activation of cerebellar granule cells GABA(A) receptors by guanidinoacetate. Neuroscience 152:65-69

Curzon G, Kantamaneni BD, Fernando JC, Woods MS, Cavanagh JB (1975) Effects of chronic porto-caval anastomosis on brain tryptophan, tyrosine and 5-hydroxytryptamine. J Neurochem 24:1065-1070

DeJoseph MR, Hawkins RA (1991) Glucose consumption decreases throughout the brain only hours after portacaval shunting. Am J Physiol 260:613-619

Faff L, Reichenbach A, Albrecht J (1997) Two modes of stimulation by ammonia of taurine release from cultured rabbit Müller cells. Neurochem Int 31:301-305

Felipo V (2006) Contribution of altered signal transduction associated to glutamate receptors in brain to the neurological alterations of hepatic encephalopathy. World J Gastroenterol 12:7737-7743

Goldbecker A, Buchert R, Berding G, Bokemeyer M, Lichtinghagen R, Wilke F, Ahl B, Weissenborn K (2010) Blood-brain barrier permeability for ammonia in patients with different grades of liver fibrosis is not different from healthy controls. J Cereb Blood Flow Metab 30:1384-1393

Gorgievski-Hrisoho M, Colombo JP, Bachmann C (1986) Stimulation of tryptophan uptake into brain microvessels by D-glutamine. Brain Res 367:395-397

Hamberger A, Nyström B (1984) Extra- and intracellular amino acids in the hippocampus during development of hepatic encephalopathy. Neurochem Res 9:1181-1192

Häussinger D (2010) Hepatic encephalopathy. Acta Gastroenterol Belg 73:457-464

Häussinger D, Görg B (2010) Interaction of oxidative stress, astrocyte swelling and cerebral ammonia toxicity. Curr Opin Clin Nutr Metab Care 13:87-92

Hawkins BT, Davis TP (2005) The blood-brain barrier/neurovascular unit in health and disease. Pharmacol Rev 57:173-185

Hawkins RA, Jessy J, Mans AM, De Joseph MR (1993) Effect of reducing brain glutamine synthesis on metabolic symptoms of hepatic encephalopathy. J Neurochem 60:1000-1006

Hawkins RA, O'Kane RL, Simpson IA, Viña JR (2006) Structure of the blood-brain barrier and its role in the transport of amino acids. J Nutr 136:218S-226S

Hazell AS, Norenberg MD (1998) Ammonia and manganese increase arginine uptake in cultured astrocytes. Neurochem Res 23:869873

Hilgier W, Zitting A, Albrecht J (1985) The brain octopamine and phenylethanolamine content in rats in thioacetamide-induced hepatogenic encephalopathy. Acta Neurol Scand 71:195-198
Hilgier W, Albrecht J, Lisy V, Stastny F (1990) The effect of acute and repeated hyperammonemia on gamma-glutamyl transpeptidase in homogenates and capillaries of various rat brain regions. Mol Chem Neuropathol 13:47-56

Hilgier W, Benveniste H, Diemer NH, Albrecht J (1991) Decreased glucose utilization in discrete brain regions of rat in thioacetamide-induced hepatic encephalopathy as measured with $[3 \mathrm{H}]$ deoxyglucose. Acta Neurol Scand 83:353-355

Hilgier W, Puka M, Albrecht J (1992) Characteristics of large neutral amino acid-induced release of preloaded L-glutamine from rat cerebral capillaries in vitro: effects of ammonia, hepatic encephalopathy, and gamma-glutamyl transpeptidase inhibitors. J Neurosci Res 32:221-226

Hilgier W, Olson JE, Albrecht J (1996) Relation of taurine transport and brain edema in rats with simple hyperammonemia or liver failure. J Neurosci Res 45:69-74

Hilgier W, Freśko I, Klemenska E, Beresewicz A, Oja SS, Saransaari P, Albrecht J, Zielińska M (2009) Glutamine inhibits ammoniainduced accumulation of cGMP in rat striatum limiting arginine supply for NO synthesis. Neurobiol Dis 35:75-81

Horowitz ME, Schafer DF, Molnar P, Jones EA, Blasberg RG, Patlak CS, Waggoner J, Fenstermacher JD (1983) Increased bloodbrain transfer in a rabbit model of acute liver failure. Gastroenterology 84:1003-1011

Huang CH, Liu PZ (2001) New insights into the Rh superfamily of genes and proteins in erythroid cells and nonerythroid tissues. Blood Cells Mol Dis 27:90-101

Ishihara T, Takada T, Shoji Y, Uedono Y, Takeyama N, Tanaka T (1998) Hyperammonemia reduces water immersion-restraint stress gastric ulcers in rats. Gen Pharmacol 31:87-91

Jalan R, Olde Damink SW, Hayes PC, Deutz NE, Lee A (2004) Pathogenesis of intracranial hypertension in acute liver failure: inflammation, ammonia and cerebral blood flow. J Hepatol 41:613-620

Jalan R, Olde Damink SW, Ter Steege JC, Redhead DN, Lee A, Hayes PC, Deutz NE (2011) Acute endotoxemia following transjugular intrahepatic stent-shunt insertion is associated with systemic and cerebral vasodilatation with increased whole body nitric oxide production in critically ill cirrhotic patients. J Hepatol 54:265-271

James JH, Hodgman JM, Funovics JM, Fischer JE (1976) Alterations in brain octopamine and brain tyrosine following portacaval anastomosis in rats. J Neurochem 27:223-227

James JH, Escourrou J, Fischer JE (1978) Blood-brain neutral amino acid transport activity is increased after portacaval anastomosis. Science 200:1395-1397

James JH, Ziparo V, Jeppsson B, Fischer JE (1979) Hyperammonaemia, plasma aminoacid imbalance, and blood-brain aminoacid transport: a unified theory of portal-systemic encephalopathy. Lancet 2:772-775

Jayakumar AR, Panickar KS, Murthy ChR, Norenberg MD (2006) Oxidative stress and mitogen-activated protein kinase phosphorylation mediate ammonia-induced cell swelling and glutamate uptake inhibition in cultured astrocytes. J Neurosci 26:47744784

Jessy J, Mans AM, DeJoseph MR, Hawkins RA (1990) Hyperammonaemia causes many of the changes found after portacaval shunting. Biochem J 272:311-317

Jiang W, Desjardins P, Butterworth RF (2009) Direct evidence for central proinflammatory mechanisms in rats with experimental acute liver failure: protective effect of hypothermia. J Cereb Blood Flow Metab 29:944-952

Kato M, Hughes RD, Keays RT, Williams R (1992) Electron microscopic study of brain capillaries in cerebral edema from fulminant hepatic failure. Hepatology 15:1060-1066 
Kircheis G, Wettstein M, Dahl S, Häussinger D (2002) Clinical efficacy of L-ornithine-L-aspartate in the management of hepatic encephalopathy. Metab Brain Dis 17:453-462

Laursen H, Schrøder H, Westergaard E (1975) The effect of portocaval anastomosis on the permeability to horseradish peroxidase of cerebral vessels of the rat. Acta Pathol Microbiol Scand A 83:266-268

Lehner C, Gehwolf R, Tempfer H, Krizbai I, Hennig B, Bauer HC, Bauer H (2011) Oxidative stress and blood-brain barrier dysfunction under particular consideration of matrix metalloproteinases. Antioxid Redox Signal. doi:10.1089/ars.2011.3923

Licinio J, Wong ML (1997) Pathways and mechanisms for cytokine signaling of the central nervous system. J Clin Invest 100:29412947

Lo WD, Ennis SR, Goldstein GW, McNeely DL, Betz AL (1987) The effects of galactosamine-induced hepatic failure upon bloodbrain barrier permeability. Hepatology 7:452-456

Lockwood AH, Yap EW, Wong WH (1991) Cerebral ammonia metabolism in patients with severe liver disease and minimal hepatic encephalopathy. J Cereb Blood Flow Metab 11:337-341

Lv S, Song HL, Zhou Y, Li LX, Cui W, Wang W, Liu P (2010) Tumour necrosis factor-alpha affects blood-brain barrier permeability and tight junction-associated occludin in acute liver failure. Liver Int 30:1198-1210

Mans AM, Davis DW, Hawkins RA (1986) Regional blood-brain barrier transport of glucose after portacaval anastomosis. Metab Brain Dis 1:119-128

Nguyen JH, Yamamoto S, Steers J, Sevlever D, Lin W, Shimojima N, Castanedes-Casey M, Genco P, Golde T, Richelson E, Dickson D, McKinney M, Eckman CB (2006) Matrix metalloproteinase-9 contributes to brain extravasation and edema in fulminant hepatic failure mice. J Hepatol 44:1105-1114

Odeh M, Sabo E, Srugo I, Oliven A (2005) Relationship between tumor necrosis factor-alpha and ammonia in patients with hepatic encephalopathy due to chronic liver failure. Ann Med 37:603-612

Okada T, Watanabe Y, Brusilow SW, Traystman RJ, Koehler RC (2000) Interaction of glutamine and arginine on cerebrovascular reactivity to hypercapnia. Am J Physiol Heart Circ Physiol 278:H1577-H1584

Oldendorf WH (1971) Brain uptake of radiolabeled amino acids, amines, and hexoses after arterial injection. Am J Physiol 221:1629-1639

Ott P, Larsen FS (2004) Blood-brain barrier permeability to ammonia in liver failure: a critical reappraisal. Neurochem Int 44:185-198

Pilbeam CM, Anderson RM, Bhathal PS (1983) The brain in experimental portal-systemic encephalopathy. I. Morphological changes in three animal models. J Pathol 140:331-345

Rao KV, Norenberg MD (2001) Cerebral energy metabolism in hepatic encephalopathy and hyperammonemia. Metab Brain Dis 16:67-78

Rao VL, Audet RM, Butterworth RF (1997) Portacaval shunting and hyperammonemia stimulate the uptake of $\mathrm{L}-[3 \mathrm{H}]$ arginine but not of $\mathrm{L}-[3 \mathrm{H}]$ nitroarginine into rat brain synaptosomes. J Neurochem 68:337-343

Rigotti P, Jonung T, Peters JC, James JH, Fischer JE (1985) Methionine sulfoximine prevents the accumulation of large neutral amino acids in brain of portacaval-shunted rats. J Neurochem 44:929-933

Sarna GS, Bradbury MW, Cavanagh J (1977) Permeability of the blood-brain barrier after portocaval anastomosis in the rat. Brain Res 138:550-554

Sarna GS, Bradbury MW, Cremer JE, Lai JC, Teal HM (1979) Brain metabolism and specific transport at the blood-brain barrier after portocaval anastomosis in the rat. Brain Res 160:69-83
Seiler N (2000) Oxidation of polyamines and brain injury. Neurochem Res 25:471-490

Shank RP, Campbell GL (1983) Ornithine as a precursor of glutamate and GABA: uptake and metabolism by neuronal and glial enriched cellular material. J Neurosci Res 9:47-57

Sheron N, Bird G, Goka J, Alexander G, Williams R (1991) Elevated plasma interleukin-6 and increased severity and mortality in alcoholic hepatitis. Clin Exp Immunol 84:449-453

Sikorska H, Cianciara J, Wiercińska-Drapało A (2010) Physiological functions of L-ornithine and L-aspartate in the body and the efficacy of administration of L-ornithine-L-aspartate in conditions of relative deficiency. Pol Merkus Lekarski 28:490-495

Simard M, Nedergaard M (2004) The neurobiology of glia in the context of water and ion homeostasis. Neuroscience 129:877896

Sinke AP, Jayakumar AR, Panickar KS, Moriyama M, Reddy PV, Norenberg MD (2008) NFkappaB in the mechanism of ammonia-induced astrocyte swelling in culture. J Neurochem 106: 2302-2311

Skowrońska M, Zielińska M, Albrecht J (2010) Stimulation of natriuretic peptide receptor $\mathrm{C}$ attenuates accumulation of reactive oxygen species and nitric oxide synthesis in ammoniatreated astrocytes. J Neurochem 115:1068-1076

Smith AR, Rossi-Fanelli F, Ziparo V, James JH, Perelle BA, Fischer JE (1978) Alterations in plasma and CSF amino acids, amines and metabolites in hepatic coma. Ann Surg 187:343-350

Sørensen M, Keiding S (2007) New findings on cerebral ammonia uptake in HE using functional (13) $N$-ammonia PET. Metab Brain Dis 22:277-284

Stastný F, Hilgier W, Albrecht J, Lisý V (1988) Changes in the activity of gamma-glutamyl transpeptidase in brain microvessels, astroglial cells and synaptosomes derived from rats with hepatic encephalopathy. Neurosci Lett 84:323-328

Sumner BE (1982) A quantitative study of vascular permeability to horseradish peroxidase, and the subsequent fate of the tracer, in rat brains after portocaval anastomosis. Neuropathol Appl Neurobiol 8:117-133

Tilg H, Wilmer A, Vogel W, Herold M, Nölchen B, Judmaier G, Huber C (1992) Serum levels of cytokines in chronic liver diseases. Gastroenterology 103:264-274

Toris GT, Bikis CN, Tsourouflis GS, Theocharis SE (2011) Hepatic encephalopathy: an updated approach from pathogenesis to treatment. Med Sci Monit 17:RA53-RA63

Wang W, Lv S, Zhou Y, Fu J, Li C, Liu P (2011) Tumor necrosis factor- $\alpha$ affects blood-brain barrier permeability in acetaminophen-induced acute liver failure. Eur J Gastroenterol Hepatol 23:552-558

Warren K (1962) Ammonia toxicity and pH. Nature 195:47-49

Warskulat U, Görg B, Bidmon HJ, Müller HW, Schliess F, Häussinger D (2002) Ammonia-induced heme oxygenase-1 expression in cultured rat astrocytes and rat brain in vivo. Glia 40:324-336

Wright G, Shawcross D, Olde Damink SW, Jalan R (2007) Brain cytokine flux in acute liver failure and its relationship with intracranial hypertension. Metab Brain Dis 22:375-388

Zaki AE, Wardle EN, Canalese J, Ede RJ, Williams R (1983) Potential toxins of acute liver failure and their effects on bloodbrain barrier permeability. Experientia 39:988-991

Zaki AE, Ede RJ, Davis M, Williams R (1984) Experimental studies of blood brain barrier permeability in acute hepatic failure. Hepatology 4:359-363

Zanchin G, Rigotti P, Dussini N, Vassanelli P, Battistin L (1979) Cerebral amino acid levels and uptake in rats after portocaval anastomosis: II. Regional studies in vivo. J Neurosci Res 4:301-310 
Zielinska M, Zablocka B, Albrecht J (2003) Effect of ammonia on taurine transport in C6 glioma cells. Adv Exp Med Biol 526:463-470

Zielińska M, Ruszkiewicz J, Hilgier W, Fręśko I, Albrecht J (2011) Hyperammonemia increases the expression and activity of the glutamine/arginine transporter $\mathrm{y}+$ LAT2 in rat cerebral cortex: implications for the nitric oxide/cGMP pathway. Neurochem Int 58:190-195

Zimmermann C, Ferenci P, Pifl C, Yurdaydin C, Ebner J, Lassmann H, Roth E, Hörtnagl H (1989) Hepatic encephalopathy in thioacetamide-induced acute liver failure in rats: characterization of an improved model and study of amino acid-ergic neurotransmission. Hepatology 9:594-601

Zwingmann C, Chatauret N, Leibfritz D, Butterworth RF (2003) Selective increase of brain lactate synthesis in experimental acute liver failure: results of a [H-C] nuclear magnetic resonance study. Hepatology 37:420-428 